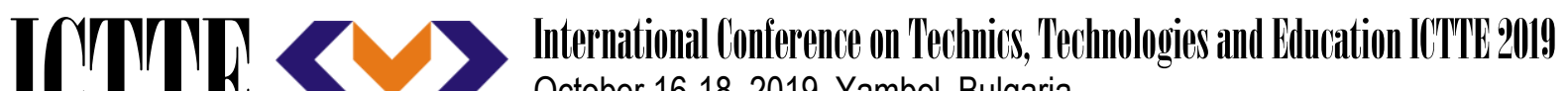 October 16-18, 2019, Yambol, Bulgaria www.ictte.eu
}

\section{COLORISTIC DESIGN OF CLOTHING ON THE BASIS OF COLOR PERCEPTION}

\author{
Masha Voznuk ${ }^{1}$, Victoria Zemlyakova, Svetlana Kuleshova \& Oksana Syrotenko \\ Khmelnitskyi National University \\ Institytska str., 11, Khmelnitskyi, Ukraine, 29016 \\ Postal address of the institution, phone/ mobile: +38(095)536-09-51, e-mail: \\ kuleshova lana@ukr.net \\ sirotenko@email.ua
}

\begin{abstract}
This work contains knowledge about a color theory that plays an important role in the process of planning the visual variety of clothing. The special attention is paid to the creation of the authors' clothing models on the base of the color perception.

The fractal structural model of perception of color is worked out. It allows taking into account character of functioning of component parts of this process.

The consumers' reactions to the color of a garment are taken into account. The consumers' color preferences from the standpoint of not only the personality of the individual, but also the sociopsychological appearance are determined.

Using the results of the current research, a designer can choose the color solution for single or serial production, as well as specify a certain color range, which can also be applied for outfits. In the last stage, a transition to the distribution of selected colors among the details of a garment is made. It takes into account the dimensions of the specific elements to obtain a harmonious combination of proportions of details.
\end{abstract}

Keywords: color theory, harmonious color palette, design, consumer, clothing, perception.

\section{INTRODUCTION}

The problems of planning clothing color are determined by the specific of perception of color by consumers. Therefore, they should be solved in a complex manner taking into account all levels of formation and perception of color.

Color related psychological studies are a phenomenon of the twentieth and twenty-first centuries. The problem of optimal color palette selection has been studied by many researchers. An overview can be found in works [1-7]. All of authors considered color palettes in relationships with person individuality and described different aspects of using these relationships in regular person life.

In works $[8,9,11]$ were described basic principles of the design clothing with account of color as one of the main elements of garment composition. Particular case of using the color palette in design of garments was shown in [7, 11-13].

Color preference tests have been devised in [10] in order to gain useful information on how people will react to certain colors in given situations, and as a means of personality analysis. In the paper, the developments of the described in [15-17] approach as a basic for the coloristic design of clothing are being continued.

Much attention is paid to the questions of the design of complex products with due regard to coloristic solutions which allow planning the variety of the produced products.

The use of mathematical apparatus and partial automation of the creative process can give the specialist opportunities to meet various demands (economical, resource conditions, the 


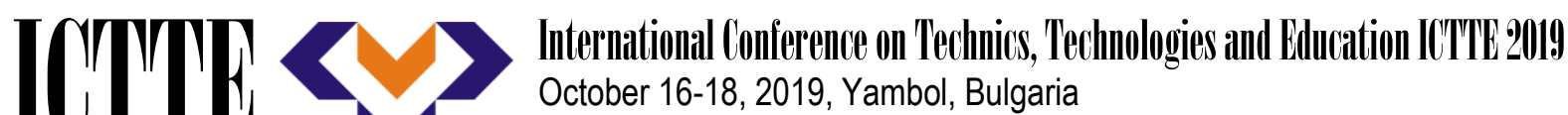 \\ www.ictte.eu}

theory of coloristic, fashion trends, etc.) in the optimum way. Therefore, the development of the research in this direction is actual and greatly requested.

\section{METHODS}

In the field of color science, a significant amount of information is collected, but there is no integrity of the synergistic approach to the aspects of color perception: 1) the study of the structure of specific color values (semantics and semiotics of color) for the formation of the planned perceptual color image; 2) the question of the role of perception of color in the system "costume" for the consumer.

Objective factors of perception of color in a suit include the color characteristics of color, the proportion of colored areas, the peculiarities of color combinations, light-colored environment. Subjective factors of perception of color include the subject and the subjective (socio-cultural) environment. The subject of perception is a person, his psychophysiological features, which are determined by sex-age characteristics, health, social status, etc.

Subjective environment - socio-cultural environment, determined by the level of development of society, its culture, tradition, ideals, etc.

Particularly important for the solution of the problems of the social and consumer complex is the creation of comfortable conditions for human perception of color in clothing.

Thus, color design is not associated with a separate color science, but covers virtually all levels of color learning. This is the specificity of color design. Therefore, the problems of color design of the project should be solved comprehensively, taking into account all levels of formation and perception of color that is shown on the Figure 1.

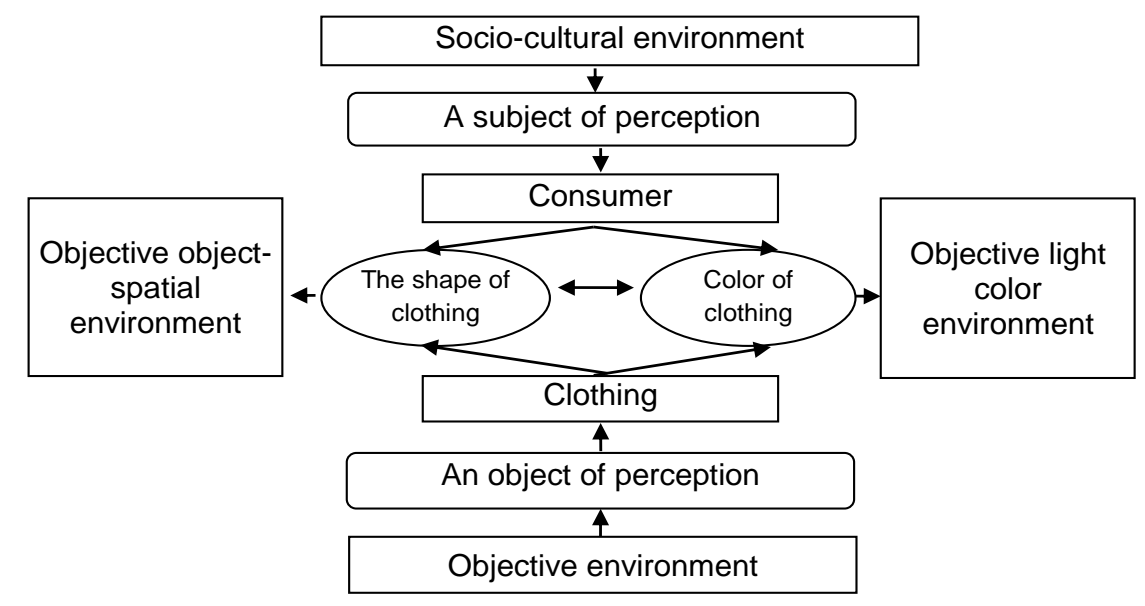

Figure 1. The structural model of color perception

The main purpose of this research is to develop practical recommendations for coloristic design of clothing on the basis of color perception.

\section{EXPERIMENTAL}

\subsection{Color design of a "costume" system based on fractal structural perceptual models of color}

Thus, the color as a means of composition in the design of a costume, necessitates its consideration in the system "culture - society - production". It is known [8] that the society Proceedings of IITTIE2019 ISSN 1314-9474 


\section{ICTTE $Y>$}

Internitionil C'onference on Technics, Technologies ind Bductition ICTTIE 2019

October 16-18, 2019, Yambol, Bulgaria

www.ictte.eu

determines in advance and regulates the development of both culture and production. Then the problem of color is investigated in three aspects of the components of the system, the structure of which is shown in Figure 2.

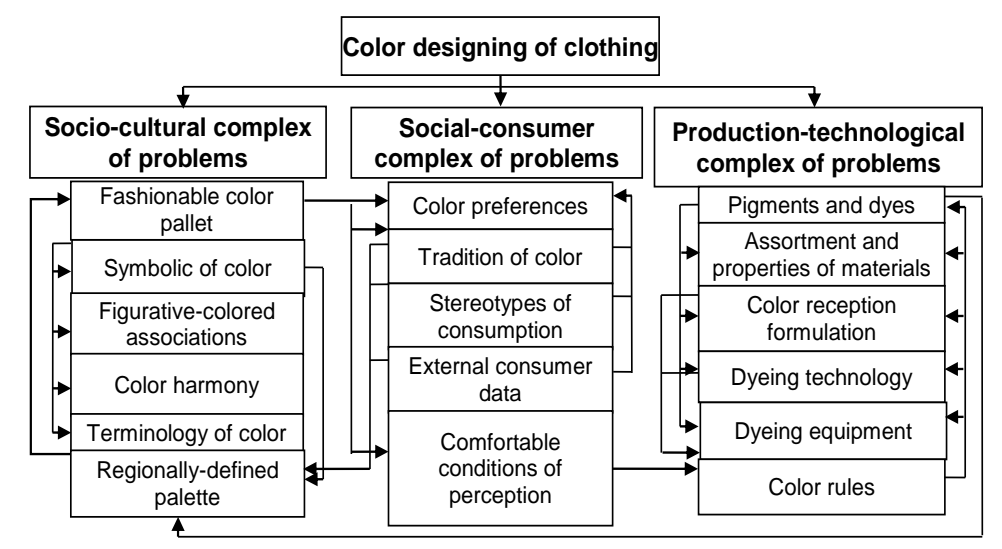

Figure 2. Three complex problems in the system of color designing of clothing

All factors of color perception are in interconnection and interaction. The developed fractal structural model of perception of color allows us to take into account the nature of the functioning of the components of this process (Fig. 3).

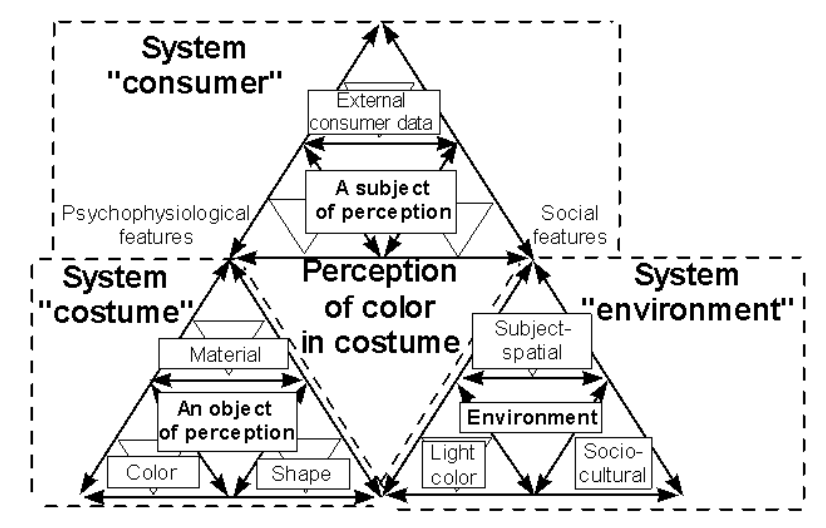

Figure 3. Fractal structural model of perception of color in costume

Allocated perception factors should be taken into account when designing a strategy for color designing of conceptual variants of perceptual images of an individual consumer.

Consideration of the fractal structural pattern of perception of color in costume determines the need for the following research:

- $\quad$ modeling of the consumer's reaction to the projected color of the product;

- $\quad$ terms of matching color and shape at all stages of designing;

- $\quad$ interconnection of the color of the object with its surrounding environment;

- definition of color preferences of the consumer from the standpoint not only of individuality, but also of socio-psychological appearance;

- construction of mathematical models for the task of finding coloring solutions of clothing models on the basis of perception. 


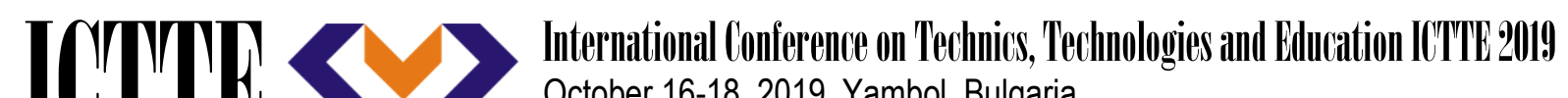 October 16-18, 2019, Yambol, Bulgaria www.ictte.eu}

\subsection{On finding coloristic solutions}

The construction of mathematical models for the problem of finding color solutions is based on the recommendations of the theory of costume design, taking into account the selection of harmonious color grades, which give the impression of color entirety and the relationship between colors of details. To research the problem of finding the optimum coloristic solution from the point of view of several criteria, we use the twelve-part color wheel [17], the fragment of which is presented in Figure 4.

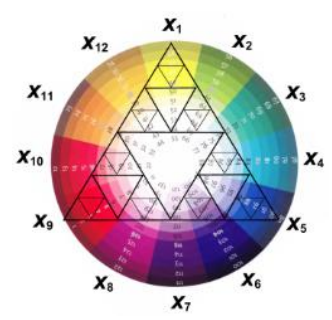

Figure 4. Fragment of the scheme of harmonious color combinations according to Wilhelm Ostwald

The color wheel is an important foundation for any aesthetic theory of color, since it gives the system of color arrangement and allows us to understand clearly the schemes of harmonious combinations.

We now turn to the construction of mathematical models for the problem of selecting the dominant color (by varying the weights), searching for optimal color combinations according to the [14]. We construct a new mathematical model. We introduce the following notations:

$J$ - the set of color numbers, $J=\{1, \ldots, n\}$;

$v_{j}$ - the color with number $j \in J$;

$x_{j}$ - a boolean variable that takes the value of true if $v_{j}$ is a part of the palette and false otherwise;

$s_{j}$ - the weight of the color according to $v_{j}, j \in J$;

$p_{1}, p_{2}$ - the lower and upper bounds for the total number of colors included in the product;

$I$ - the set of logical formula numbers used in the model $I \in\{1, \ldots, m\}$;

$C_{i}$ - the logical formula corresponding to the $i$-th constraint, which is the disjunction of variables and/or their negations;

The task is to find the values of the logical variables that limit the total number of colors included in the product, and formulas $C_{i}, i \in l$, are satisfied, and the weight of the colors included in the gamut will be maximum.

Similar to the previous model we denote by $y_{1}, \ldots, y_{n}$ boolean variables, that $y_{j}$ corresponds to literal $x_{j}$, and $\left(1-y_{1}\right)$ corresponds to literal $\bar{x}_{j}, j=\{1, \ldots, n\}$..

The problem of integer linear programming for the case under consideration is as follows:

$$
\begin{gathered}
f=\sum_{j \in J} s_{j} y_{j} \rightarrow \max , \\
\sum_{j \in C_{i}^{-}} y_{j}-\sum_{j \in C_{i}^{+}} y_{j} \leq 1-\left|C_{i}^{-}\right|, \quad i \in I, \\
p_{1} \leq \sum_{j \in J} y_{j} \leq p_{2},
\end{gathered}
$$




\section{ITTIL $\>$}

Internitionil C'onference on Technics, Technologies ind Bductition ICTTIE 2019

October 16-18, 2019, Yambol, Bulgaria

www.ictte.eu

$$
\begin{aligned}
& 0 \leq y_{j} \leq 1, y_{j} \in Z, j \in J, \\
& 0 \leq z_{i} \leq 1, z_{i} \in Z, i \in I,
\end{aligned}
$$

All the conditions of a harmonious combination of colors (2) considered in the problem are constraints of a hard type. Condition (3) determines the possible number of colors in the found gamma. As the result of solving these problems, the user will receive a set of color scales that satisfy the set conditions.

\section{RESULTS}

As input data for the current research it is advisable to use the recommendations that were described in $[4,7-10,13,15-17]$. The examples of such recommendations for the creation of the authors' clothing of models on the base of the color perception are presented in the tables 1-5 and in Figures 5-7.

Example 1: The monochrome composition of the costume ensemble involves the presence of one color tone sector of the color wheel of different degrees of light and saturation. Using the use of the "shadow line" in the costume reach color harmony and achieve a balance of holistic costume uniforms. Impression: calmness, refinement, a sense of space, Figure 5, table 1.

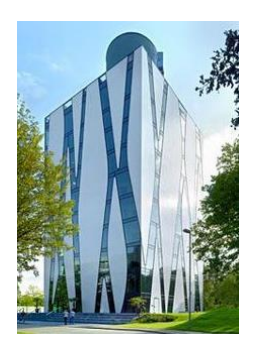

a

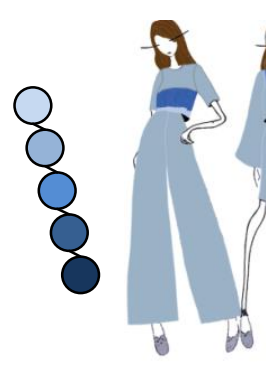

b

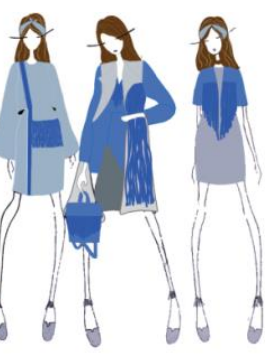

C
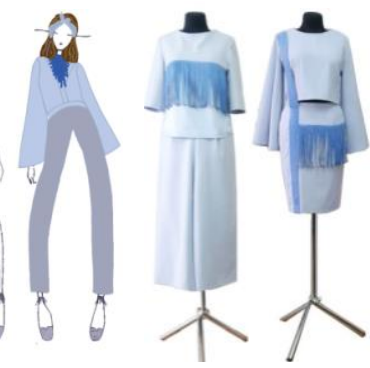
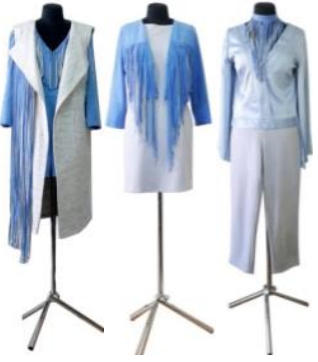

d

Figure 5. The source of creativity (a), color scheme (b), sketches (c) and photo of the author's collection of ensembles by the motto "Free Space" (d)

\begin{tabular}{|c|c|c|c|c|c|c|c|c|}
\hline \multirow{2}{*}{$\begin{array}{l}\text { Group } \\
\text { of hues }\end{array}$} & \multirow{2}{*}{ Color } & \multirow{2}{*}{ Association } & \multirow{2}{*}{$\begin{array}{l}\text { Alternative } \\
\text { name }\end{array}$} & \multicolumn{4}{|c|}{$\begin{array}{c}\text { Tint percentage in } \\
\text { color } \%\end{array}$} & \multirow{2}{*}{ Impression } \\
\hline & & & & $\mathrm{C}$ & $\mathrm{M}$ & $\mathrm{Y}$ & $\mathrm{K}$ & \\
\hline \multicolumn{9}{|c|}{ Blue color } \\
\hline \multirow{2}{*}{$\begin{array}{l}\text { Light } \\
\text { hues }\end{array}$} & Pale blue & $\begin{array}{l}\text { delicate, cold, } \\
\text { calm }\end{array}$ & $\begin{array}{l}\text { Aquamarine } \\
\text { Heavenly blue }\end{array}$ & 25 & 10 & 10 & 00 & \multirow{2}{*}{$\begin{array}{l}\text { Bright tones nice and } \\
\text { peaceful. In delicate blue } \\
\text { shades combine calm and } \\
\text { elegant elegance. }\end{array}$} \\
\hline & Light-blue & $\begin{array}{l}\text { cold, romantic, } \\
\text { fresh }\end{array}$ & $\begin{array}{l}\text { Calcareous } \\
\text { Lagoon }\end{array}$ & 44 & 20 & 08 & 00 & \\
\hline \multirow{3}{*}{$\begin{array}{l}\text { Bright } \\
\text { hues }\end{array}$} & Indigo & $\begin{array}{c}\text { precious, stately } \\
\text { posh }\end{array}$ & $\begin{array}{c}\text { Iris } \\
\text { Azure }\end{array}$ & 81 & 40 & 03 & 00 & \multirow{3}{*}{$\begin{array}{l}\text { Bright shades of blue are } \\
\text { active, energetic, luxurious, } \\
\text { bold and cheerful. }\end{array}$} \\
\hline & Neon & $\begin{array}{l}\text { cold, sports, } \\
\text { youth }\end{array}$ & $\begin{array}{l}\text { Ultramarine } \\
\text { Electrician }\end{array}$ & 100 & 50 & 00 & 00 & \\
\hline & Hyacinth & $\begin{array}{c}\text { active, cheerful, } \\
\text { sporty }\end{array}$ & $\begin{array}{c}\text { Cobalt } \\
\text { Kerosene }\end{array}$ & 100 & 60 & 00 & 14 & \\
\hline
\end{tabular}

Table 1. Blue in clothing 


\section{ITTIE $\$}

Internitional Conference on Technics, Technologies ind Edurcation ICTTIE 2019

October 16-18, 2019, Yambol, Bulgaria

www.ictte.eu

Example 2: The polar harmony uses two opposite colors in the color wheel. These colors enhance each other, creating a visual vibration effect. The scheme is noticeable, dynamic and creates a lively dramatic effect, tables 2,3 , Figure 6.

Table 2. Types of color contrasts

\begin{tabular}{|l|c|c|}
\hline Types of color contrast & Characteristic & Impression \\
\hline $\begin{array}{l}\text { Contrast of } \\
\text { complementary colors }\end{array}$ & $\begin{array}{c}\text { This is a combination of colors that are opposite } \\
\text { each other in the color wheel. This type of } \\
\text { contrast is most impressive, since each } \\
\text { combination of colors contains a strong contrast } \\
\text { of light and dark, as well as cold and warm }\end{array}$ & $\begin{array}{c}\text { Expression, } \\
\text { vibration, feeling } \\
\text { of space, } \\
\text { complete balance } \\
\text { and harmony }\end{array}$ \\
\hline
\end{tabular}

Table 3. Yellow and blue color in clothing

\begin{tabular}{|c|c|c|c|c|c|c|c|c|}
\hline \multirow{2}{*}{$\begin{array}{l}\text { Group } \\
\text { of hues }\end{array}$} & \multirow[t]{2}{*}{ Color } & \multirow[t]{2}{*}{ Association } & \multirow{2}{*}{$\begin{array}{l}\text { Alternative } \\
\text { name }\end{array}$} & & \multicolumn{2}{|c|}{ Tint percentage } & $\begin{array}{l}\text { age } \\
0\end{array}$ & \multirow[t]{2}{*}{ Impression } \\
\hline & & & & C & $M$ & $\mathrm{Y}$ & $\mathrm{K}$ & \\
\hline \multicolumn{9}{|c|}{ Yellow color } \\
\hline $\begin{array}{l}\text { Bright } \\
\text { hues }\end{array}$ & $\begin{array}{c}\text { Yellow } \\
\text { primrose }\end{array}$ & $\begin{array}{l}\text { blinding, } \\
\text { cheerful, } \\
\text { sightly }\end{array}$ & $\begin{array}{l}\text { Yolk } \\
\text { Lemon }\end{array}$ & 00 & 00 & 81 & 00 & $\begin{array}{l}\text { Bright hues are impressive and } \\
\text { energetic. They charge with cheer } \\
\text { and optimism. }\end{array}$ \\
\hline \multicolumn{9}{|c|}{ Blue color } \\
\hline $\begin{array}{l}\text { Dark } \\
\text { hues }\end{array}$ & $\begin{array}{l}\text { Lead } \\
\text { blue }\end{array}$ & $\begin{array}{l}\text { strong, } \\
\text { serious, } \\
\text { decisive }\end{array}$ & Patriotic & 100 & 70 & 00 & 28 & $\begin{array}{c}\text { Restrained, balanced and } \\
\text { conservative. They demonstrate } \\
\text { authority, dignity, power. }\end{array}$ \\
\hline
\end{tabular}

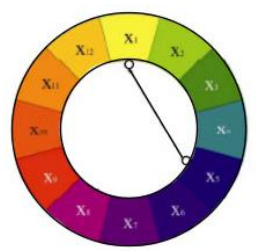

a

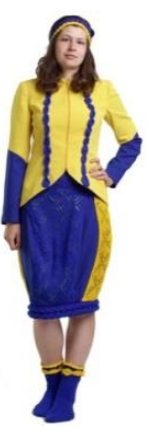

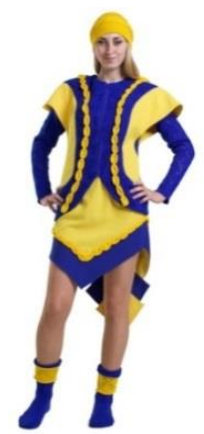

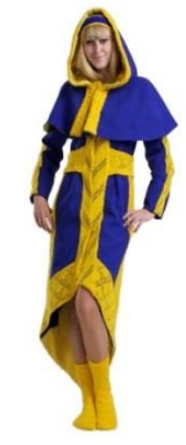

b
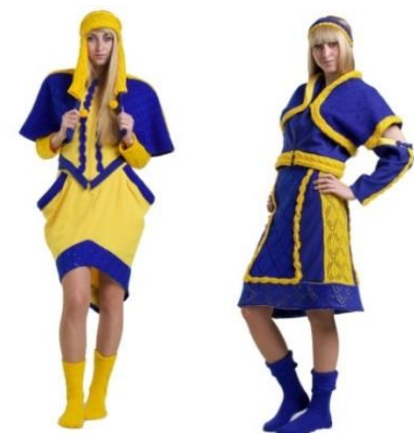

Figure 6. Color scheme (a) and photo of the author's collection of ensembles by the motto

"Shield of the Nation" (b)

Example 3: The typological group of color harmonies is the polychrome harmony of achromatic colors with chromatic: a rich red color with white and black, tables 4, 5, Figure 7.

Table 4. Types of color contrasts

\begin{tabular}{|l|c|c|}
\hline Types of color contrast & \multicolumn{1}{|c|}{ Characteristic } & Impression \\
\hline Contrast of areas of & $\begin{array}{c}\text { Colors can be combined with each other in } \\
\text { different proportions in clothing. The force of } \\
\text { influence is determined by two factors: the } \\
\text { color spots }\end{array}$ & $\begin{array}{c}\text { From the } \\
\text { dramatic-formal to } \\
\text { the softly delicate }\end{array}$ \\
\hline
\end{tabular}




\section{IITTIE $Y$}

Internitional Conference on Technics, Technologies ind Bducation ICTTLE 2019 October 16-18, 2019, Yambol, Bulgaria www.ictte.eu

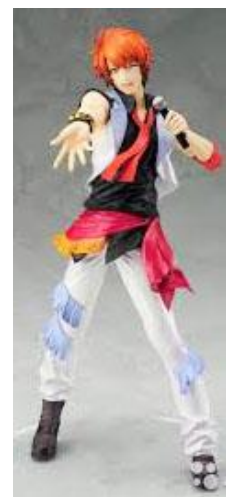

a

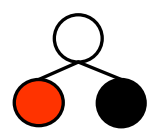

b

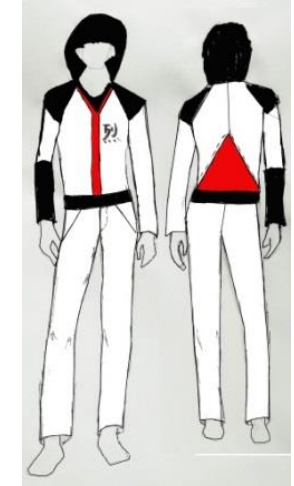

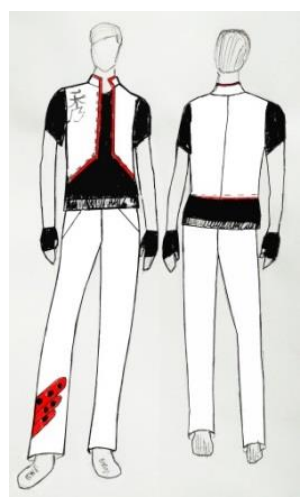

C

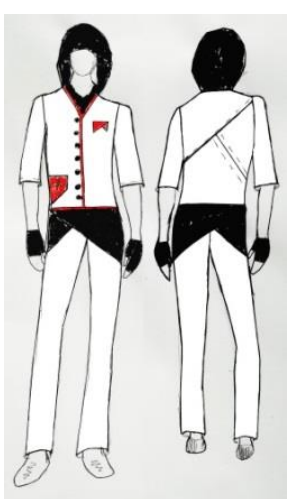

Figure 7. The source of creativity (a), color scheme (b), sketches of the author's collection of ensembles by the motto "Sports - the eternal classics" (c)

Table 5. Red, white and black color in clothing

\begin{tabular}{|c|c|c|c|c|c|c|c|c|}
\hline \multirow{2}{*}{$\begin{array}{l}\text { Group } \\
\text { of hues }\end{array}$} & \multirow[t]{2}{*}{ Color } & \multirow[t]{2}{*}{ Association } & \multirow{2}{*}{$\begin{array}{l}\text { Alternative } \\
\text { name }\end{array}$} & \multicolumn{4}{|c|}{$\begin{array}{l}\text { Tint percentage } \\
\text { in color \% }\end{array}$} & \multirow[t]{2}{*}{ Impression } \\
\hline & & & & C & $M$ & $\mathrm{Y}$ & $\mathrm{K}$ & \\
\hline \multicolumn{9}{|c|}{ Red color } \\
\hline $\begin{array}{l}\text { Bright } \\
\text { hues }\end{array}$ & Red & $\begin{array}{l}\text { active, live, } \\
\text { benevolent }\end{array}$ & $\begin{array}{l}\text { Cherry } \\
\text { Strawberry }\end{array}$ & 00 & 82 & 70 & 00 & $\begin{array}{l}\text { Bright hues are active and } \\
\text { passionate. They express } \\
\text { emotions, energy and power. }\end{array}$ \\
\hline \multicolumn{9}{|c|}{ White color } \\
\hline $\begin{array}{l}\text { White } \\
\text { hues }\end{array}$ & White & $\begin{array}{l}\text { serious, } \\
\text { strong, } \\
\text { decisive }\end{array}$ & $\begin{array}{l}\text { The color of } \\
\text { white roses } \\
\text { Lily color } \\
\text { Marble }\end{array}$ & 00 & 00 & 00 & 25 & $\begin{array}{l}\text { Light and carefree. They } \\
\text { radiate purity, harmony and } \\
\text { flawlessness. They combine } \\
\text { minimalism, calm and } \\
\text { aristocracy. }\end{array}$ \\
\hline \multicolumn{9}{|c|}{ Black color } \\
\hline $\begin{array}{l}\text { Black } \\
\text { hues }\end{array}$ & Black & $\begin{array}{c}\text { authoritative, } \\
\text { conservative, } \\
\text { serious }\end{array}$ & $\begin{array}{l}\text { Wet asphalt } \\
\text { Black iron }\end{array}$ & 00 & 00 & 00 & 75 & $\begin{array}{l}\text { Variable and varied. May be } \\
\text { sinister, magical, luxurious, } \\
\text { and youthful. }\end{array}$ \\
\hline
\end{tabular}

Thus, it is confirmed that the choice of a harmonious color palette, which creates the impression of color integrity and the relationship between the colors of details of the model of clothing, is important. The results of experiments confirmed the prospects of applying the developed approach to obtain a number of different solutions based on the perception of color.

\section{CONCLUSIONS}

Thus, color harmony is a function of the interaction between colors and the factors that influence positive aesthetic response to color: individual differences such as age, gender, personality and affective state; cultural experiences, the prevailing context which includes setting and ambient lighting; intervening perceptual effects and the effects of time in terms of prevailing social trends. 


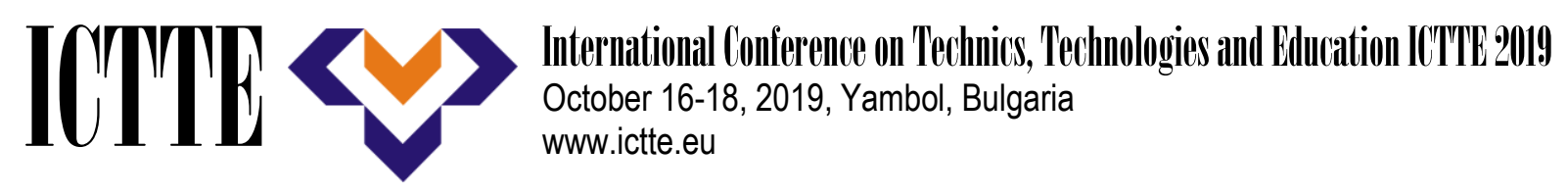

The information we have obtained can be used as a basis for expert system. Such system is intended for make a decision about selection of colors and fabric for the garment. Input data in system must be the list of colors properties, garment type, and consumer type. The rules of selection the colors are formed in the tables 1-5. Thus these tables form the basis of the simple knowledge-base system.

\section{REFERENCES}

[1]. Luscher M. (1977). The 4-Color Person. New York, Simon and Schuster, ISBN 0-67124232-6. (1977).

[2]. Jackson C. (1987). Color Me Beautiful. New York, The Random House Publishing Group, (1987).

[3].Spillane M. \& Sherlock, Ch. (1995). Color Me Beautiful's Looking Your Best: Color, Makeup and Style. Lanham, Maryland, Madison Books, (1995).

[4].Webster R. (2006). Color magic for Beginners. Minnesota, Llewellyn Publication Woodbury, (2006).

[5]. Henderson V., \& Henshaw P. (2006). Colour Me Beautiful: Colour me confident. London, Hamlyn, (2006).

[6]. Henderson V., \& Henshaw P. (2010). Colour Me Beautiful: Change Yours Truly, Look Change Your Life. London, Hamlyn, (2010).

[7]. Freer A. (2015). How to Get Dressed: A Costume Designer's Secrets for Making Your Clothes Look, Fit, and Feel Amazing. New York, Ten Speed Press, (2015).

[8]. Kozlova T. V. (1988). The fundamentals of the theory of design costume. Moscow, Legprombytizdat, (1988).

[9]. Medvedeva, T. V. (2005). The costume's design. Moscow, FORUM: INFRA, (2005).

[10]. Radeloff D. J. (1990). Role of color in perception of attractiveness. Percept, and Mot. Skills. Vol. 71, No. 1, (1990), pp. 151-160.

[11]. Korobtseva N. A., \& Petrova E. A. (1998). Clothes as an object of psychological research. Clothing industry, Vol. 4, (1998), pp. 36-37.

[12]. Korobtseva N. A. (2001). Designing clothes: an impressive approach: monograph. Moscow, GNOME and D, (2001).

[13]. Korobtseva N. A. (2005). Formation of individual image and design of clothes: current problems and research directions. Imageology 2005: phenomenology, theory, practice. Proceedings of the Third International Symposium. Moscow, (2005), pp. 323-325. Available: June 5, 2015 from http://imageology.ru/content/view/46/30/

[14]. Kolokolov A. A., Artemova A. V., Adelshin A. V., \& Kan I. E. (2016). Discrete Optimization Models for Solving Complex Products Design Problems Proc. DOOR 2016, Vladivostok, Russia, September 19-23, 2016. CEUR-WS. Vol. 1623, (2016), pp. 49 - 56. CEUR-WS.org, online http://ceur-ws.org/Vol-1623/paperco9.pdf

[15]. Kuleshova S. G., Slavinska A.L.., Zakharkevich O. V., \& Shvets G. S. (2016). Evaluation of the level of harmonisation of clothes, International Conference on Research in Education and Science. Proceeding book, (2016), pp. 1544-1552. Bodrum: Gaziantep University.

[16]. Kuleshova S. G., Slavinska A.L., Zakharkevich O. V., \& Shvets G. S. (2017). Image clothing as a perceptual component of clothing design. Textiles, clothing, leather and technologies, Vol. 3, (2017), pp.12-20.

[17]. Kuleshova S. G. (2016). Color in the art of designing clothes: study guide. Khmelnytskyi: KhNU, (2016). 